\title{
On human body transmission wearable diamond dipole antennas above engineered jackets
}

\author{
Muhammad Azfar bin Abdullah ${ }^{1}$, Mohamad Kamal A. Rahim² ${ }^{2}$, Noor Asmawati Samsuri ${ }^{3}$, \\ Mohd Fairus ${ }^{4}$, Mohd Khairul Hisham Ismail ${ }^{5}$, Huda A. Majid ${ }^{6}$ \\ ${ }^{1,5}$ Agensi Angkasa Malaysia, Selangor, Malaysia \\ ${ }^{2,3,4}$ Communication Engineering Department, Faculty of Electrical Engineering, \\ University Technology Malaysia, Johor, Malaysia \\ ${ }^{6}$ Faculty of Engineering Technology (FTK) Department Electrical Engineering Technology, \\ Universiti Tun Hussein Onn Malaysia, Johor, Malaysia
}

\section{Article Info}

Article history:

Received Feb 18, 2020

Revised Jun 12, 2021

Accepted Jun 13, 2021

Keywords:

Dipole

Dual-band transmission

Dual-band waveguide

\begin{abstract}
This paper presents the propagation of dual-band diamond dipole antenna on three various jackets. The jackets are purely fleece fabric with Shieldit fabric patches on top of it. The network analyzers with the flexible lossless coaxial cable are used to measure the communication of the antennas. The experiment involves a man with ideal body mass index (BMI) wearing the jackets by placing the flexible antennas on top of it. It is observed that the best on-body communication is by wearing the engineered jacket. The $10 \mathrm{~dB}$ improvements are observed when the antenna is positioned on top of engineered jacket contrast to the regular jacket. In other words, the performance of the antenna is also be determined by antenna placement. High transmission lossesses cause the antenna mismatch when the antennas are positioned above the full conductive jacket.
\end{abstract}

This is an open access article under the CC BY-SA license.

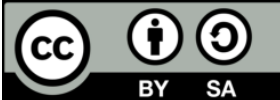

\section{Corresponding Author:}

Muhammad Azfar bin Abdullah

Agensi Angkasa Malaysia

Turi Banting St.

42700 Selangor, Malaysia

Email: azfar87@gmail.com

\section{INTRODUCTION}

Recently, on human body communication network is famous among the teenagers. Human body can be said as a portion of body-centric wireless communication, which consists of the integration of wireless personal area network (WPN) and wireless sensor network (WSN). Besides, the wearable wireless networking devices such as the electronic gadgets become simple and smaller when the transmission flows throughout the human body.

Previously, textile antennas have been investigated seriously since 1999 [1]-[9] to have the robustness and wearable antenna. The fabrics that have been used as substrate are felt fabric, jeans fabric and fleece fabric. However, the antenna is not able to perform well due to the behaviour of the human body [10]-[13]. The common coaxial port which is bulky size and rigid is not suitable for wearable use [14], [15].

The reseachers have studied a different method to overcome the deteroriation of the antenna's performance. Aritificial magnetic conductor (AMC) has been integrated with the antenna to increase the antenna's performance. The main characteristic of the AMC [16] may increase the antenna's performance in terms of reflection coofecient, propogation and radiation pattern. Previous researchers have proved that the 
used of the structure reduced the unwanted radiation and increased the antenna's performance [17], [18]. Sheet-like waveguide sheet is proposed [19]-[25] if the antenna is positioned near the human body. The structure can improve the antenna communication and decrease the transmission losses [26].

This paper investigated the propagation between two dual-band textile dipole antennas with three kinds of jackets; regular jacket, full conductive jacket and engineered jacket. The transmission of the antenna is measured in two orientations for jackets. The transmission of the antenna are compared and discussed. The performance of antenna ontegrated with waveguide jacket has improved significantly compared to the other jackets.

\section{RESEARCH METHOD}

Before the measurements are conducted, three types of jackets made by fleece fabric are fabricated. They are called regular jacket, full ground plate jacket and engineered jacket. Regular jacket is a normal jacket with no any conductive element as shown in Figure 1 (a). Full conductive jacket has attached with Shiledit fabric as shown in Figure 1 (b) while the engineered jacket is a structure from my previous work [14]. The conductive patches are made by Shieldit super fabric. Two similar dual-band diamond dipole antennas have been used to be integrated with the jackets as shown in Figure 1.

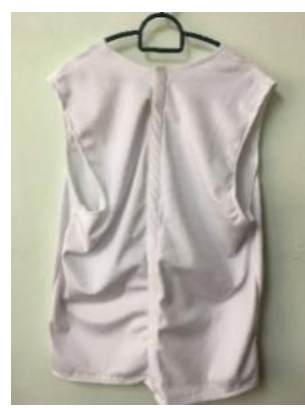

(a)

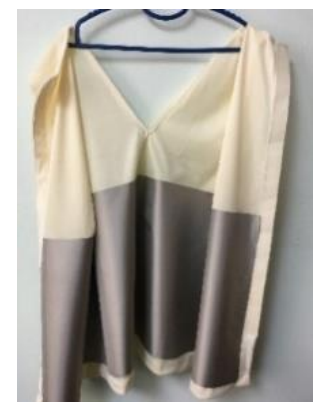

(b)

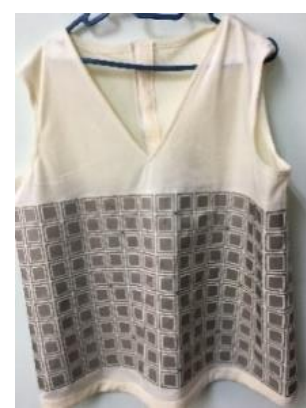

(c)

Figure 1. Photo of jackets: (a) reguler jacket, (b) full conductive jacket, (c) waveguide jacket

In this paper, the positioning of the antenna placement on top of the jackets is examined. The antennas are positioned up-down and left-right respectively above the jacket as presented in Figure 2. A transmitter (Tx) antennas is located at the centre of the jacket. Eight different positions with labelled alphabetically from A to $\mathrm{H}$ are placed around the Tx. The distance between them is fix at $14 \mathrm{~cm}$ as shown in Figure 3. In this experiment, a man wore the jackets with the antennas in a small space area. Figure 4 displays the setup of the measurement. $3 \mathrm{~mm}$ gap between both antennas and the jacket is fix by putting a piece of foam $\left(\sigma_{\mathrm{r}}=1\right)$. In this experiment, the $S_{21}$ of the antennas is measured by using portable network analyser.

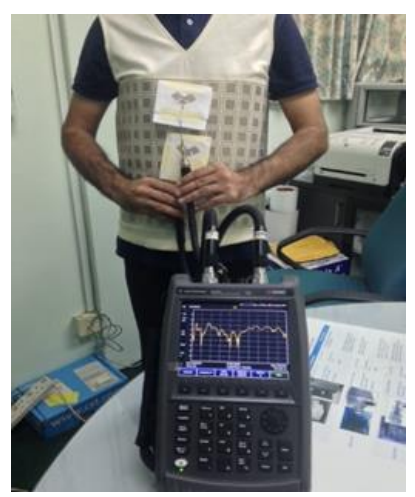

(a)

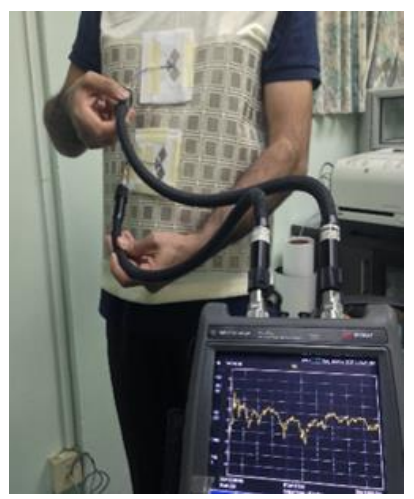

(b)

Figure 2. Antenna orientation: (a) horizontal orientation and (b) vertical orientation 


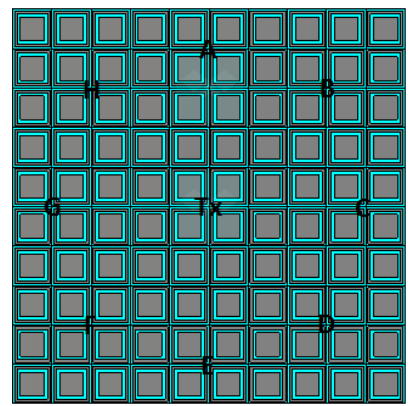

Figure 3. Positions of the Rx antenna

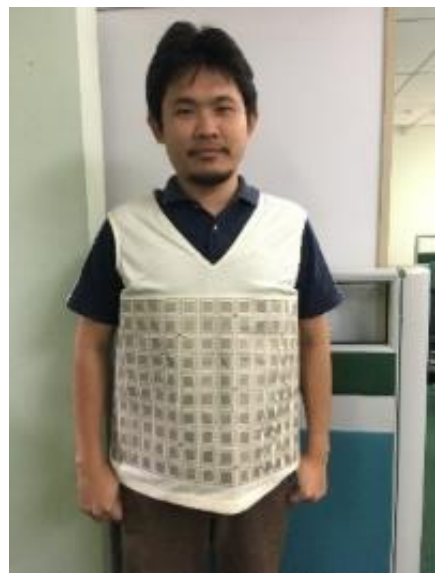

Figure 4. Snapshot of the experiment

\section{RESULTS AND DISCUSSION}

Further investigation is carried out to explore the best position of dual-band diamond dipole above engineered jacket, full conductive jacket and regular jacket. Figures 5, 6 and 7 show the $S_{21}$ transmission between antennas above three types of jackets. When the antennas are placed vertically, good transmission between both antennas occur at position $\mathrm{C}$ and $\mathrm{G}$ as shown in Figure 5 and 7 . If the antennas are placed horizontally, position $\mathrm{A}$ and $\mathrm{E}$ give the best transmission between the antennas. Good communication between the antennas depend on the position of the antenna In other words, to have a good transmission, both antennas must be at the same polarization. From the results, it shows that the arrangement of the antenna is important to have good transmission. The antenn's pattern contributes to the good transmission. While the waveguide jacket allows the antennas wave propagates through it to have better transmission.

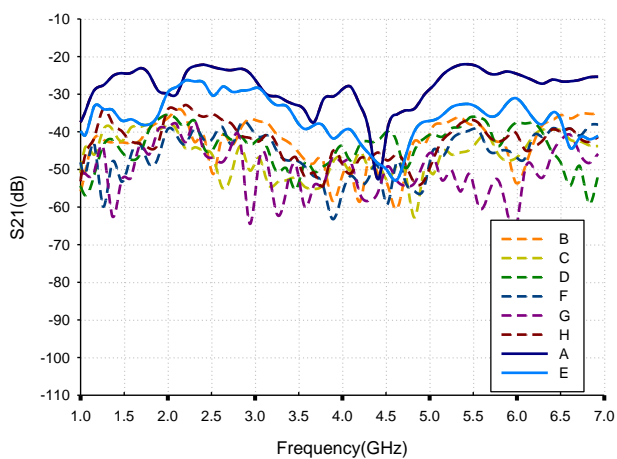

(a)

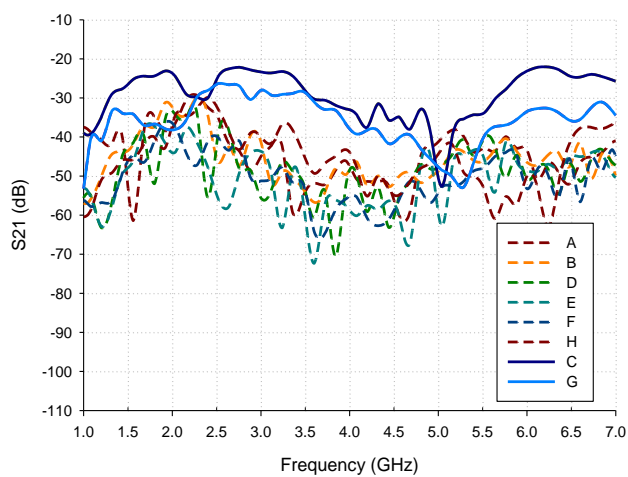

(b)

Figure 5. $\mathrm{S}_{21}$ transmission of dual-band diamond dipole above engineered jacket:

(a) horizontal orientation and (b) vertical orientation 


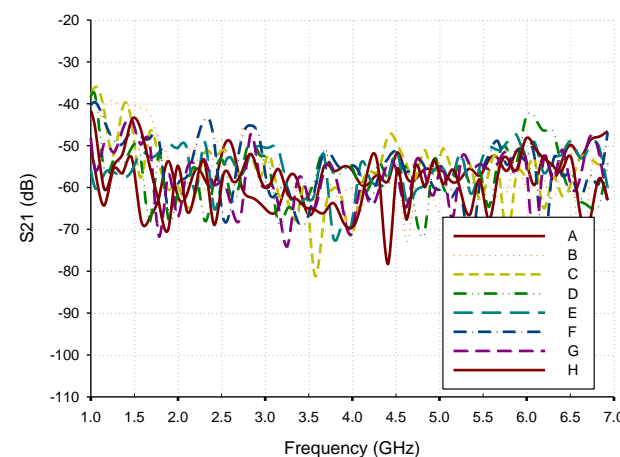

(a)

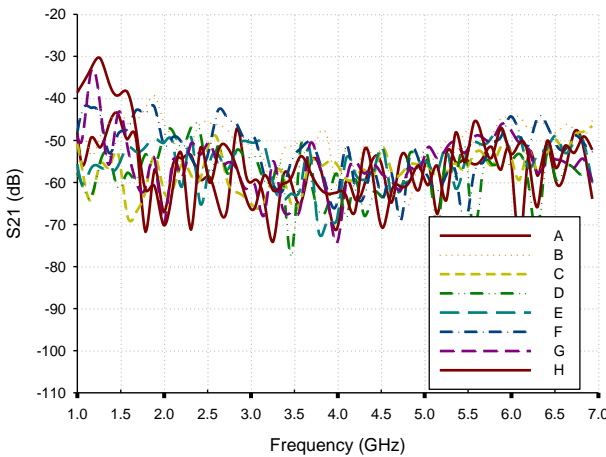

(b)

Figure 6. $\mathrm{S}_{21}$ transmission of dual-band diamond dipole above full conductive jacket:

(a) horizontal orientation and (b) vertical orientation

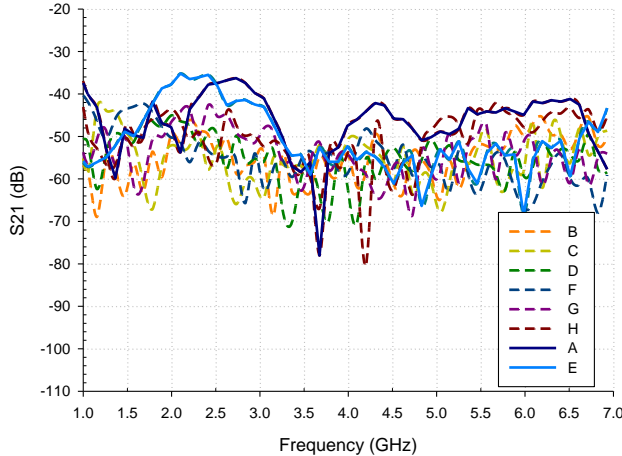

(a)

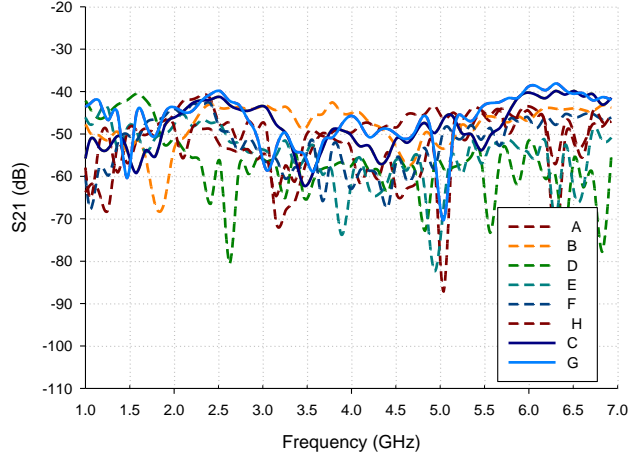

(b)

Figure 7. $\mathrm{S}_{21}$ transmission of dual-band diamond dipole above regular jacket

(a) horizontal orientation and (b) vertical orientation

The measurement results are compared in Figure 8. As can be observed, the high $\mathrm{S}_{21}$ peak with $-22 \mathrm{~dB}$ at $2.45 \mathrm{GHz}$ and $-24 \mathrm{~dB}$ at $5.8 \mathrm{GHz}$ at position $\mathrm{A}$ in horizontal polarization. The high $\mathrm{S}_{21}$ peak with $-20 \mathrm{~dB}$ at $2.45 \mathrm{GHz}$ and $-25 \mathrm{~dB}$ at $5.8 \mathrm{GHz}$ at position $\mathrm{C}$ in vertical polarization. The high $\mathrm{S}_{21}$ peak is contributed by having AMC surface beneath it. The high $S_{21}$ peak for transmission between antennas above the normal jacket with $-38 \mathrm{~dB}$ at $3.45 \mathrm{GHz}$ and $-40 \mathrm{~dB}$ at $5.8 \mathrm{GHz}$. Lower $\mathrm{S}_{21}$ peak is observed compared to the waveguide jacket because of human body effect. High transmission losses occurred when placed near to the lossy human body. From the Figure 6, the $S_{2} 1$ transmission between antennas above the grounding jacket are in noise level with $-60 \mathrm{~dB}$. This is because the antenna suffer a very high mismatch and transmission loss above the full conductive jacket.

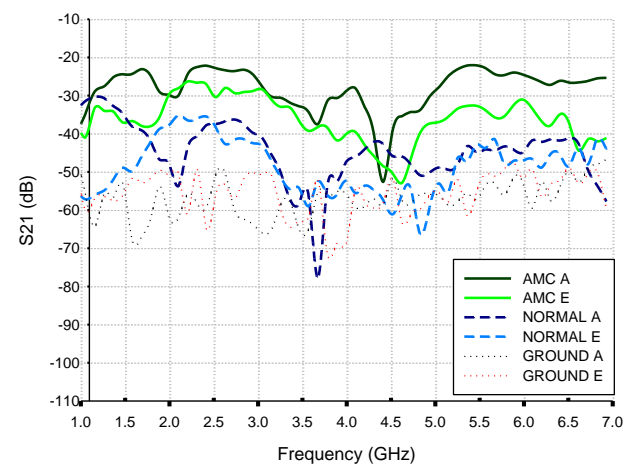

(a)

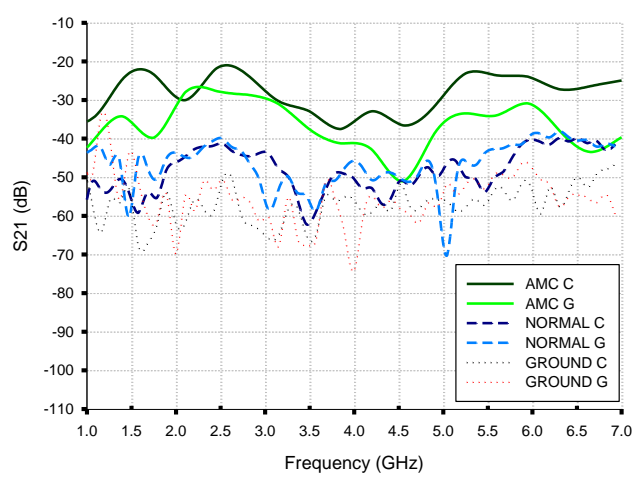

(b)

Figure 8. Comparison $\mathrm{S}_{21}$ transmission of dual-band diamond dipole above three jackets: (a) horizontal polarization and (b) vertical polarization 


\section{CONCLUSION}

As conclusion, two wearable antenna with regular jacket, full conductive jacket and engineered jacket have been fabricated and measured. The position of the antenna above jacket need to be considered in achieving better antenna's transmission. The engineered jacket offers clear transmission route and lower the transmission loss because of AMC characteristic. The in-phase reflection characteristic can increase the antennas' communication. Meanwhile, the full conductive jacket cause the antenna mismatch and not appropriate for antenna transmission.

\section{ACKNOWLEDGEMENTS}

The authors express gratitude the Ministry of education (MOE) for supporting the research work; Advanced RF and Microwave Research Group (ARFMRG), School of Postgraduate Studies (SPS), Research Management Centre (RMC), School of Electrical Engineering, Faculty of Engineering, and Universiti Teknologi Malaysia (UTM) Johor Bahru for the support of the research under grant no 04G67.

\section{REFERENCES}

[1] P. Salonen, L. Sydanheimo, M. Keskilammi, and M. Kivikoski, "A small planar inverted-F antenna for wearable applications," Digest of Papers. Third International Symposium on Wearable Computers, 1999, pp. 95-100, doi: 10.1109/ISWC.1999.806679.

[2] S. Subramaniam and B. Gupta, "Design and Development of Body-Worn Applications and its Performance Study Under Flat and Bent Positions," Microwave and Optical Technology Letters, vol. 53, no. 9, pp. 2004-2011, 2011, doi: 10.1002/mop.26188.

[3] S. Zhu and R. Langley, "Dual-Band Wearable Textile Antenna on an EBG Substrate," in IEEE Transactions on Antennas and Propagation, vol. 57, no. 4, pp. 926-935, April 2009, doi: 10.1109/TAP.2009.2014527.

[4] T. F. Kennedy, P. W. Fink, A. W. Chu, N. J. Champagne, G. Y. Lin, and M. A. Khayat, "Body-Worn E-Textile Antennas: The Good, the Low-Mass, and the Conformal," in IEEE Transactions on Antennas and Propagation, vol. 57, no. 4, pp. 910-918, April 2009, doi: 10.1109/TAP.2009.2014602.

[5] Y. Hao, P. S. Hall, and K. Ito, "IEEE Transactions on Antennas and Propagation Announces Special Issue on Antennas and Propagation for Body-Centric Wireless Communications," in IEEE Antennas and Propagation Magazine, vol. 49, no. 4, pp. 201-201, Aug. 2007, doi: 10.1109/MAP.2007.4385641.

[6] P. S. Hall and Y. Hao, "Antennas and propagation for body centric communications," 2006 First European Conference on Antennas and Propagation, 2006, pp. 1-7, doi: 10.1109/EUCAP.2006.4584864.

[7] A. W. Astrin, H.-B. Li, and R. Kohno, "Standardization for Body Area Networks," IEICE transactions on communications, vol. E92-B, no. 2, pp. 366-372, 2009, doi: 10.1587/transcom.E92.B.366.

[8] E. Jovanov, A. Milenkovic, C. Otto, and P. C. de Groen, "A Wireless Body Area Network of Intelligent Motion Sensors for Computer Assisted Physical Rehabilitation," Journal of NeuroEngineering and Rehabilitation, vol. 2, no. 1, pp. 1-10, Mar. 2005, doi: 10.1186/1743-0003-2-6.

[9] P. Hall, Y. Hao, and K. Ito, "Guest Editorial for the Special Issue on Antennas and Propagation on Body-Centric Wireless Communications," in IEEE Transactions on Antennas and Propagation, vol. 57, no. 4, pp. 834-836, April 2009, doi: 10.1109/TAP.2009.2018564.

[10] M. Tanaka and Jae-Hyeuk Jang, "Wearable microstrip antenna," IEEE Antennas and Propagation Society International Symposium. Digest. Held in conjunction with: USNC/CNC/URSI North American Radio Sci. Meeting (Cat. No.03CH37450), 2003, pp. 704-707 vol.2, doi: 10.1109/APS.2003.1219333.

[11] Qammer H. Abbasi, Masood Ur Rehman, Khalid Qaraqe, and Akram Alomainy, "Advances in Body-Centric Wireless Communications: Applications and Stateof- the-art," The Institution of Engineering and Technology (IET) Publication, July, 2016

[12] M. M. Khan, Q. H. Abbasi, A. Alomainy, and C. Parini, "Experimental Investigation of Subject-Specific On-Body Radio Propagation Channels for Body-Centric Wireless Communications," Electronics, vol. 3, pp. $26-42$. doi:10.3390/electronics3010026. ISSN 2079-9292.

[13] Amr M. E. Safwat, "Body-Centric Wireless Communications," Antennas \& Electromagnetics Research Group, Retrieved 19 December 2015.

[14] L. Liu, S. Zhu, and R. Langley, "Dual-band Triangular Patch Antenna with Modified Ground Plane," Electronics Letters, vol. 43, no. 3, pp. 5-6, 2007, doi: 10.1049/el:20073643.

[15] M. A. bin Abdullah, M. K. A. Rahim, M. E. bin Jalil, N. A. Samsuri, and N. A. Murad, "Integrated two textile dipole antenna with dual-band textile artificial magnetic conductor," 2013 7th European Conference on Antennas and Propagation (EuCAP), 2013, pp. 2075-2078.

[16] L. Ma, R. M. Edwards, and W. G. Whittow, "A notched hand wearable ultra wideband W printed monopole antenna for sporting activities," 2008 Loughborough Antennas and Propagation Conference, 2008, pp. 397-400, doi: 10.1109/LAPC.2008.4516950.

[17] M. A. bin Abdullah, M. K. A. Rahim, M. E. bin Jalil, N. A. Samsuri, and N. A. Murad, "Integrated two textile dipole antenna with dual-band textile artificial magnetic conductor," 2013 7th European Conference on Antennas and Propagation (EuCAP), 2013, pp. 2075-2078. 
[18] M. S. Pimenta, F. Ferrero, P. Brachat, P. Ratajczak, R. Staraj and J. M. Ribero, "Textile artificial magnetic conductor for GPS applications," 2012 6th European Conference on Antennas and Propagation (EUCAP), 2012, pp. 2884-2886, doi: 10.1109/EuCAP.2012.6206447.

[19] K. Eom and H. Arai, "Smart suit: Wearable sheet-like waveguide for body-centric wireless communications," The 3rd European Wireless Technology Conference, 2010, pp. 1-4.

[20] Maizatun Muhamad, Maisarah Abu, Zahriladha Zakaria, Hasnizom Hassan, "Novel Artificial Magnetic Conductor for 5G Application," Indonesian Journal of Electrical Engineering and Computer Science, vol. 5, no. 3, pp. 636-642, March 2017, doi: 10.11591/ijeecs.v5.i3.pp636-642.

[21] K. Eom and H. Arai, "Smart blanket: Flexible and easy to couple waveguide," 2011 IEEE Topical Conference on Biomedical Wireless Technologies, Networks, and Sensing Systems, 2011, pp. 15-18, doi: 10.1109/BIOWIRELESS.2011.5724343.

[22] K. Kamardin, M. K. A. Rahim, P. S. Hall, N. A. Samsuri, M. E. Jalil, and M. Z. Anuar, "Textile waveguide sheet with Artificial Magnetic Conductor structures for body centric wireless communication," 2012 IEEE Asia-Pacific Conference on Applied Electromagnetics (APACE), 2012, pp. 257-261, doi: 10.1109/APACE.2012.6457672.

[23] M. A. Abdullah, M. K. A. Rahim, and N. A. Samsuri, "On-Body Communication System Transmission Enhancement Using a Dual-Band Textile Artificial Magnetic Conductor," Advanced Science Letters, vol. 23, no. 11, pp. 11298-11301, 2017, doi: 10.1166/asl.2017.10270.

[24] Emad Shehab Ahmed, "Wearable Conformal Antennas for $2.4 \mathrm{GHz}$ Wireless Body Area Networks," TELKOMNIKA Telecommunication Computing Electronics and Control, vol. 11, no. 1, pp. 175-180, Mar. 2013, doi: 10.12928/telkomnika.v11i1.768.

[25] A. Ashyap, et al., "Flexible Wearable Antenna on Electromagnetic Band Gap using PDMS substrate," TELKOMNIKA Telecommunication Computing Electronics and Control, vol. 15, no. 3, pp. 1454-1460, Sep. 2017, doi: 10.12928/TELKOMNIKA.v15i3.7214.

[26] K. Priyanka, and S. Khobragade, "Red Tacton Human Area Networking," International Journal of Computer and Electronics Research, vol. 2, no. 2, pp. 2278-5795, 2013.

\section{BIOGRAPHIES OF AUTHORS}
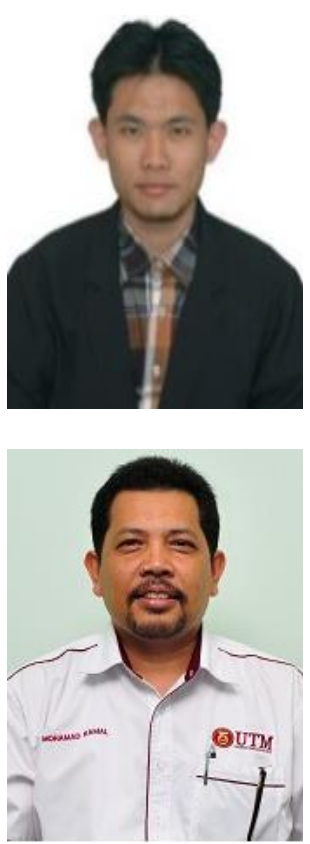

Muhammad Azfar bin Abdullah received the B Eng. degree in Electrical Engineering (Telecommunications) with honours from University Teknologi Malaysia, in 2010. He then also obtained his M.Eng (Electrical Engineering) in 2014, at same university. He is currently an on going $\mathrm{PhD}$ in Electrical Engineering at School of Engineering at Universiti Teknologi Malaysia. His research interest includes the areas of design of wearable antenna and artificial magnetic conductor structure. Currently he joined department of space systems and operations, as a research officer of Malaysia Space Agency (MYSA).

Mohamad Kamal A. Rahim received the B Eng. degree in Electrical and Electronic Engineering from University of Strathclyde, UK, in 1987. From 1987 to 1989, he worked as a Management Trainee at Sime Tyres Mergong Alor Star Kedah and Production Supervisor at Sime Shoes in Kulim Kedah. In 1989, he joined the Department of Communication Engineering, Faculty of Electrical Engineering Universiti Teknologi Malaysia Kuala Lumpur as an Assistant Lecturer A. He obtained his M.Eng Science from University of New South Wales Australia in 1992 and $\mathrm{PhD}$ degrees in Electrical Engineering from University of Birmingham UK in 2003. After he received his Master he was appointed as a Lecturer at Faculty of Electrical Engineering. In 2005 he was appointed as a senior lecturer and in 2007 he was appointed as Assoc Professor at the faculty. Now he is the Professor in RF and Antenna at Faculty of Electrical Engineering Universiti Teknologi Malaysia. His research interest includes the areas of design of Dielectric resonator antennas, microstrip antennas, small antennas, microwave sensors, RFID antennas for readers and tags, Multi-function antennas, microwave circuits, EBG, artificial magnetic conductors, metamaterials, phased array antennas, computer aided design for antennas and design of millimeter frequency antennas. He has published over 200 articles in journals and conference papers. He is a co author of a book title basic principle telecommunication and several book chapters and editor of three book chapters. He has been appointed as a reviewer for several journals papers at National and International level. He has supervised 25 Phd, 60 Master which includes thesis, project report, dissertation and more than 100 undergraduate students. 12 Phd and 50 Master students have been graduated through his supervision. 

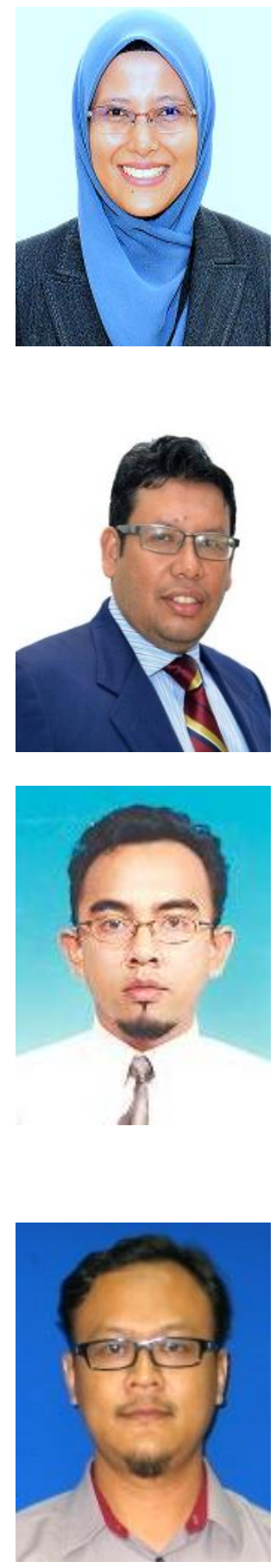

Noor Asmawati Samsuri received the B.Eng. (Hons) in Electrical-Telecommunication Engineering from Universiti Teknologi Malaysia in 2001, the MSc. in Digital Communications System from Loughborough University, UK in 2004 and the Ph.D. in Electronic and Electrical Engineering from Loughborough University, UK in 2009. She is presently a Senior Lecturer in the Faculty of Electrical Engineering, Universiti Teknologi Malaysia. Her research interests include wearable antennas including the interaction with human body and metallic items, implantable antenna for medical telemetry, and Specific Absorption Rate (SAR). During her carrier, she has been authored or co-authored several technical papers and book chapters related to her research interests. She has also been appointed as a reviewer for several journal papers at National and International level. Noor Asmawati Samsuri is a member of Board of Engineer Malaysia (BEM) and a member of IEEE (MIEEE), and is currently supervising a $\mathrm{PhD}$, Master and Undergraduate students.

Mohd Fairus is a graduate faculty member of the faculty of Electrical Engineering, UTM. He joined UTM in 2002 as a Tutor. He received his Bachelor in Engineering (ElectricalTelecommunication) in 2002 and Master of Electrical Engineering (Electrical-Electronics and Telecommunications) in 2005 from University Technology Malaysia. He obtained his Ph.D in 2012 from University of Rennes 1, France in area of Signal Processing and Telecommunication. His main research interest and areas is antenna design, millimetre waves and microwave devices. To date he has written more than five papers, which has been published in National and International conferences.

Mohd Khairul Hisham Ismail was born in Terengganu, Malaysia on August 31, 1979. He received the B. Eng. (Electrical-Telecommunication) and the M. Eng. (Electrical). Degrees from Universiti Teknologi Malaysia, Malaysia in 2001 and 2004, respectively. He is graduated $\mathrm{Ph}$. D from Universiti Teknologi Malaysia, majoring in radio communication engineering in 2014. From January 2005, he joined department of space systems and operations, as a research officer of Malaysia Space Agency (ANGKASA). As a research officer, he has been involved in satellite design projects such as RF system and electrical power system. He also conducted research and design on Electrical Power System for CubeSat project. In 2006, he joined a research project called MAGDAS (Magnetic Data Acquisitions System) to expand Global Monitoring of the Earth's Magnetic Field along Magnetic Equator with Space Environment Research Centre, Kyushu University, Japan. In 2009, he involved on designing and development of Assembley, Integration and Test Facilities at National Space Center. He has responsibility to design an Electromagnetic Compatibility Chamber for Military Standard.

Huda A. Majid received the B Eng. degree in Electrical Engineering (Telecommunication) from Universiti Teknologi Malaysia, in 2007. He then obtained his M.Eng in 2010 and PhD degrees in Electrical Engineering in 2013, at Universiti Teknologi Malaysia. He is currently a lecturer in the Department of Electrical Engineering Technology, Faculty of Engineering Technology, Universiti Tun Hussein Onn Malaysia. His research interest includes the areas of design of microstrip antennas, small antennas, Reconfigurable antennas, metamaterials structure, metalaterial antennas and millimeter wave antennas. He has published over 100 articles in journals and conference papers. 